\title{
Effect and associated factors of a clinical pharmacy model in the incidence of medication errors (EACPharModel) in the Hospital Pablo Tobón Uribe: study protocol for a stepped wedge randomized controlled trial (NCT03338725)
}

J. Granados ${ }^{1,2^{*}}$ (D, A. Salazar-Ospina ${ }^{1,2}$, J. P. Botero-Aguirre ${ }^{3}$, A. F. Valencia-Quintero ${ }^{1,3}$, N. Ortiz ${ }^{3}$ and P. Amariles ${ }^{1}$

\begin{abstract}
Background: According to $\mathrm{WHO}$, medication error (ME) is a subject that requires attention at all levels of care to reduce severe and preventable damage related to medication use. Clinical pharmacy practice standards have been proposed around the world so that the pharmacist, as part of a multidisciplinary health team, can help improve patient safety; however, further evidence derived from adequate studies is needed to demonstrate this. This study aims to assess the effect of a clinical pharmacy practice model (CPPM) in preventing MEs associated with the medication use process.

Methods: A prospective, stepped-wedge, cluster-randomized, controlled trial with a duration of 14 months will be performed to compare the effect of a CPPM along with the usual care process of patients in the Pablo Tobón Uribe Hospital (Medellin, Colombia). The study is designed as a cluster-randomized controlled trial, involving five hospital wards (clusters) and 720 patients. Medical wards are allocated to interventions using a stepped-wedge design. Clusters are initially assigned to the control group. After a 2-month observation period, hospital clusters were randomly allocated to the intervention group. Study outcomes will be assessed at baseline and at 2, 4, 6, 8, 10, and 12 months after randomization. The primary outcome will be to assess the effect of a CPPM on the incidence of medication errors associated with the medication use process. Drug-related problems and factors that contribute to the occurrence of MEs will be assessed as secondary outcomes. Statistical analyses will be performed using a mixed model, with the treatment group and time as fixed effects and the clustering structure as a random effect. Statistical analysis will be performed using Pearson chi-square tests and Student's t-tests, and a $P$ value $<0.05$ will be considered statistically significant.

(Continued on next page)
\end{abstract}

\footnotetext{
* Correspondence: elkyn.granados@udea.edu.co

'Grupo Promoción y Prevención Farmacéutica, Facultad de Ciencias

Farmacéuticas y Alimentarias, Universidad de Antioquia, Calle 70 No 52-21,

Medellín, Colombia

${ }^{2}$ Grupo de investigación en Tecnología en Regencia de Farmacia,

Universidad de Antioquia U de A, Calle 70 No 52-21, Medellín, Colombia

Full list of author information is available at the end of the article
}

(c) The Author(s). 2020 Open Access This article is distributed under the terms of the Creative Commons Attribution 4.0 International License (http://creativecommons.org/licenses/by/4.0/), which permits unrestricted use, distribution, and reproduction in any medium, provided you give appropriate credit to the original author(s) and the source, provide a link to the Creative Commons license, and indicate if changes were made. The Creative Commons Public Domain Dedication waiver (http://creativecommons.org/publicdomain/zero/1.0/) applies to the data made available in this article, unless otherwise stated. 
(Continued from previous page)

Discussion: As far as we know, this is the first stepped-wedge, cluster-randomized, controlled trial designed to assess the change of a CPPM on the incidence of medication errors in a hospital in Colombia, and it could generate valuable information about a standardized and patient-centered clinical pharmacy model to improve the safety of inpatient care.

Trial registration: ClinicalTrials.gov, NCT03338725. Registered on 9 November 2017. The first patient was randomized on 2 February 2018.

Protocol version: 0010112018JG

Keywords: Medication errors, Drug-related problems, Pharmacy service, Hospital (clinical pharmacy services), Pharmacists,

\section{Background}

The report published by the United States Institute of Medicine entitled "To err is human, building a safer health system" identified the serious problem with medical errors in the healthcare system. Medical error represents a severe public health problem that may have implications for patient safety and may contribute to a considerable increase in the cost of health care [1]. The report also indicated that during hospital care, approximately $4 \%$ of hospitalized patients are at risk of suffering some damage caused by health care errors or adverse events, of which $70 \%$ may generate temporary disability and $14 \%$ fatal incidents, causing between 44,000 and 98, 000 deaths each year $[1,2]$. For the year 2013, the annual mortality due to avoidable errors in health care in the United States was estimated as being at least 251,000 deaths [3].

Approximately $37 \%$ of adverse events that occur during the health care process are related to medication errors (ME). Medication errors in a hospital may represent between 8.0 and $19.6 \%$ of drug administrations, particularly during the prescription and medication administration process [4]. According to the National Coordinating Council of Medication Error Reporting and Prevention (NCC MERP), a medication error is defined as "any preventable event that may cause or lead to inappropriate medication use or patient harm while the medication is under the control of the health care professional, patient, or consumer." These errors may be associated with any phase of the drug delivery process, from prescription to drug administration, at any place where medications are administered [5].

The World Health Organization (WHO) in the last decade has focused its efforts on patient safety, implementing a series of actions aimed at reducing adverse events related to health care [6,7] as well as correcting deficiencies in different health systems that may lead to medication errors and severe health damage. According to these initiatives and based on safety reports related to the incidence of medication errors, different strategies have been implemented as a global initiative to reduce medication errors, including, for example, the implementation of clinical pharmacy services, where the pharmacist plays a fundamental role in the healthcare team as a support professional in the optimization of pharmacotherapy [8] as well as in the active search for medication errors and the promotion of pharmacological safety strategies. These strategies help to prevent unnecessary associated injuries during the therapeutic use of medications [9-14]. Some studies suggest that pharmacists make no significant contribution to the reduction in MEs, but they can reduce preventable adverse drug events. However, a need exists for highquality studies to explore the effect of the pharmacists on patient safety [15].

In mid-2016, the Pablo Tobón Uribe Hospital (PTUH), a highly complex university institution in the city of Medellin (Colombia), standardized a clinical pharmacy practice model that incorporated the activities of the pharmacist into the multidisciplinary health team to provide clinical pharmacy services [16] and to improve patient safety. Currently, this model is actively applied in the hospital; however, knowledge of the full effect of the model on patient safety, as framed in the WHO initiative to reduce medication errors, is needed [17]. The EACPharModel study aims to assess the effectiveness of a clinical pharmacy practice model in reducing the incidence of medication errors in a tertiary university hospital.

\section{Methods/Design \\ Design}

A 14-month, randomized, controlled, prospective, single-center, stepped-wedge, clinical trial will be performed to compare the effect of a CPPM in the incidence of medication errors.

A stepped-wedge cluster-randomized trial is proposed because the randomization of patients is not possible and because of ethical issues. A randomized cluster trial would be difficult to conduct because the cluster number would be high, and half of the clusters would not benefit from the intervention $[18,19]$. 
A stepped-wedge randomized trial designs involves the sequential roll-out of an intervention to participants over several periods, and by the end of the study, all participants will have received the intervention, although the order in which participants receive the intervention is determined at random. The clusters will be hospital wards. Each hospital cluster will start with a control period (Baseline S0) and switch to an interventional period after randomization. The study design will be composed of six consecutive 60day periods (Fig. 1). During each 60-day period, one further hospital cluster will switch to the interventional period, until all the clusters are in the interventional period during the final 60-day period. The randomization by the trial methodologist will define the point at which each hospital cluster will switch from the control to the interventional periods (Table 1).

\section{Setting}

The study is to be conducted with hospitalized patients who presented at the Pablo Tobón Uribe Hospital and were prescribed five or more drugs during their hospital stay. PTUH is a tertiary care university hospital with 483 beds (395 adults and 88 pediatrics). Adult beds are distributed in 17 hospital wards and three intensive care units (ICU); however, for this study, five hospital wards will be used, including mainly the internal medicine and orthopedic/infectious disease specialties because these wards have the largest number of patients.

\section{Study population}

The study will recruit 720 patients, and a pharmacist will evaluate whether each patient meets all the inclusion criteria.

The inclusion criteria will be the following:

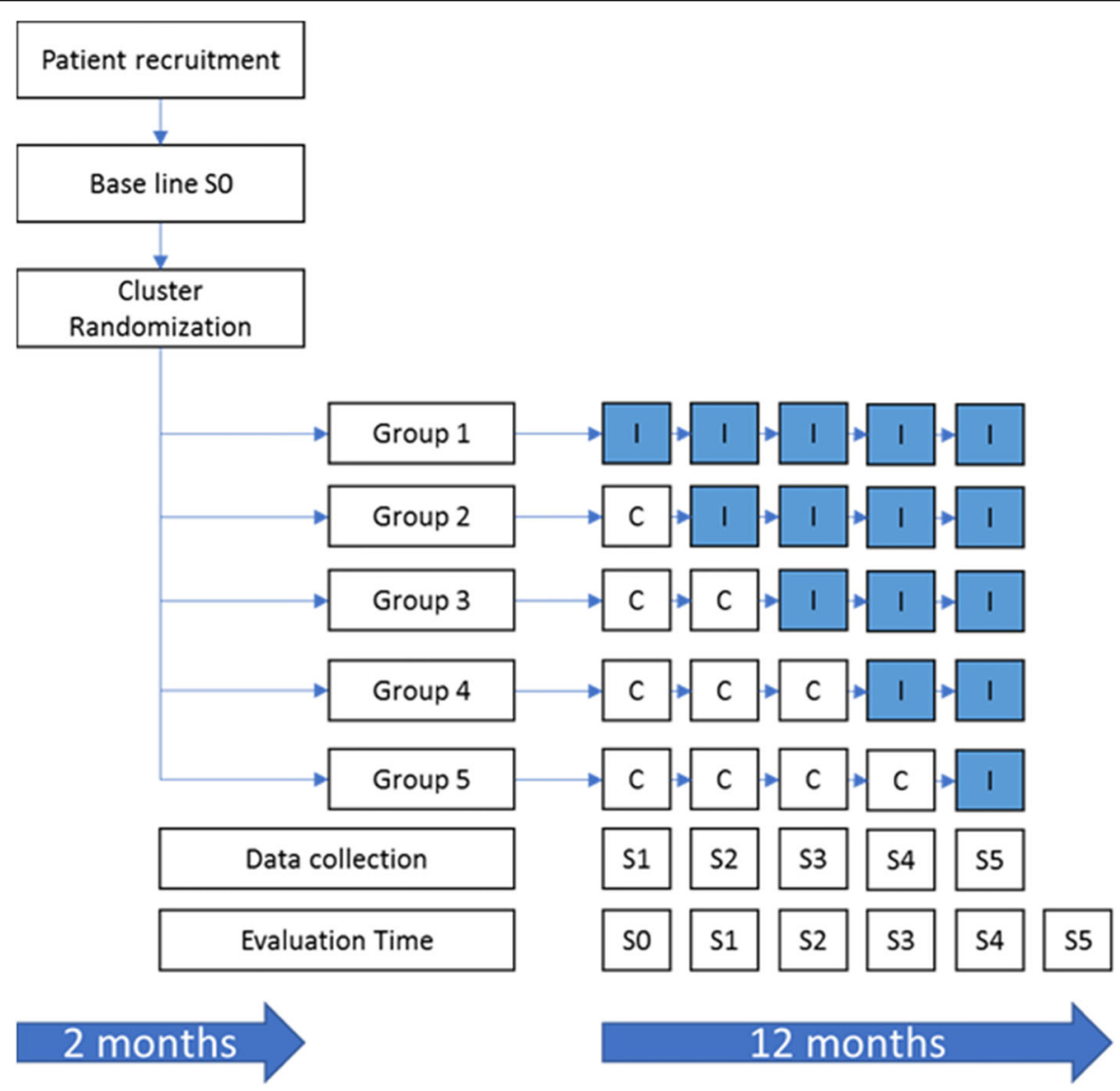

c Usual care process

1 Clinical Pharmacy Practice Model

Fig. 1 Design and timeframe of the EACPharModel study. The outcomes to be assessed during each evaluation stage are the incidence of medication error, time to the error discovery, and time to error recovery 
Table 1 Clusters, participants in the control period, and switching period

\begin{tabular}{llll}
\hline Hospital cluster (Hospital ID) & Main specialty & Participants in the control period & Intervention starting period \\
\hline B-08-1 & Internal medicine and surgery & Pharmacy technicians & Period 1 \\
B-05-2 & Internal medicine & Pharmacy technicians & Period 2 \\
B-03-1 & Orthopedics & Pharmacy technicians & Period 3 \\
B-08-2 & Internal medicine & Pharmacy technicians & Period 4 \\
B-07-2 & Internal medicine & Pharmacy technicians & Period 5 \\
\hline
\end{tabular}

- Patients at least 18 years old

- Hospitalized patients in the Pablo Tobón Uribe Hospital

- Patients receive at least five drugs in their pharmacological therapy

The exclusion criterion is a ward stay of less than $24 \mathrm{~h}$. Withdrawal criteria include the following:

- Protocol deviation and violation

- Decrease of drug prescriptions to four or fewer during the hospital stay

\section{Patient recruitment and group assignment}

A pharmacist is responsible for the recruitment of potential patients to the hospitalization wards. A hospitalization ward will be defined as a cluster, and 2 months are considered a step. For step 0 or baseline, no cluster will have the intervention; for step 1, a cluster will be randomly selected to receive the intervention and continue until the end of the study; and at step 2, another cluster will be randomly selected to receive the intervention and continue until the end of the study; this will continue until step 5 , when all clusters will have the intervention and the inclusion of the participants within the cluster will be dynamic.

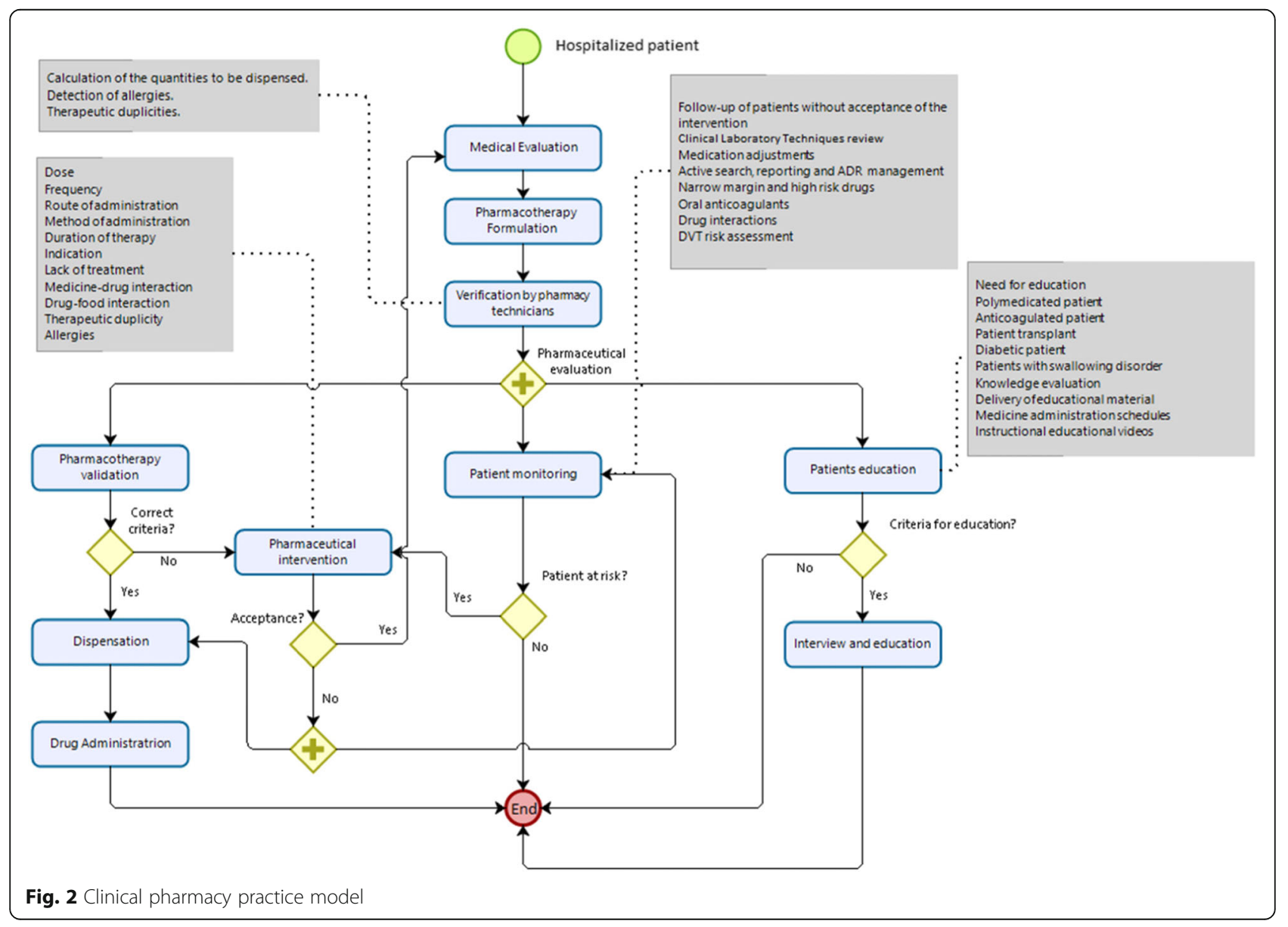


The study procedures and assessments are outlined in the Standard Protocol Items: Recommendations for Interventional Trials (SPIRIT) and are shown in Fig. 2.

\section{Outcomes}

The primary outcome to be measured will assess whether the clinical pharmacy model can change the incidence of medication errors. Among the secondary outcomes are the following: 1) the quantification and classification of medication errors, 2) identification of the factors that contribute to the occurrence of medication errors, and 3) estimation of the probability that a subject remains without medication errors and the measurement of the time until medication errors will resolve.

\section{Intervention design}

\section{Intervention group}

Attention under the clinical pharmacy practice model of the hospital is focused on the following activities: (1) participation in medical rounds (at least 3 days per week); (2) therapeutic monitoring, which consists of reviewing patients' medical records and providing verbal or written follow-up concerning their clinical conditions (involves repeated monitoring, with review of all medication orders and documentation of pharmaceutical interventions); (3) identification and management of adverse drug reactions (ADR), which consists of detecting potential ADR, providing and documenting appropriate follow-up until the ADR has resolved, and reporting ADRs to the national pharmacovigilance program; (4) pharmacological counselling to patients, which involves providing information about the proper use of medications to patients and/or family members during the hospital stay or after discharge; (5) pharmacotherapy validation, in which pharmacists conduct an appropriate review of medical orders and determine, for example, the correct dosage, correct frequency, correct route of administration, correct administration, correct duration of therapy, indicated drugs, contraindicated drugs, lack of treatment, drugdrug interactions, drug-food interactions, therapeutic duplicity, and allergies.

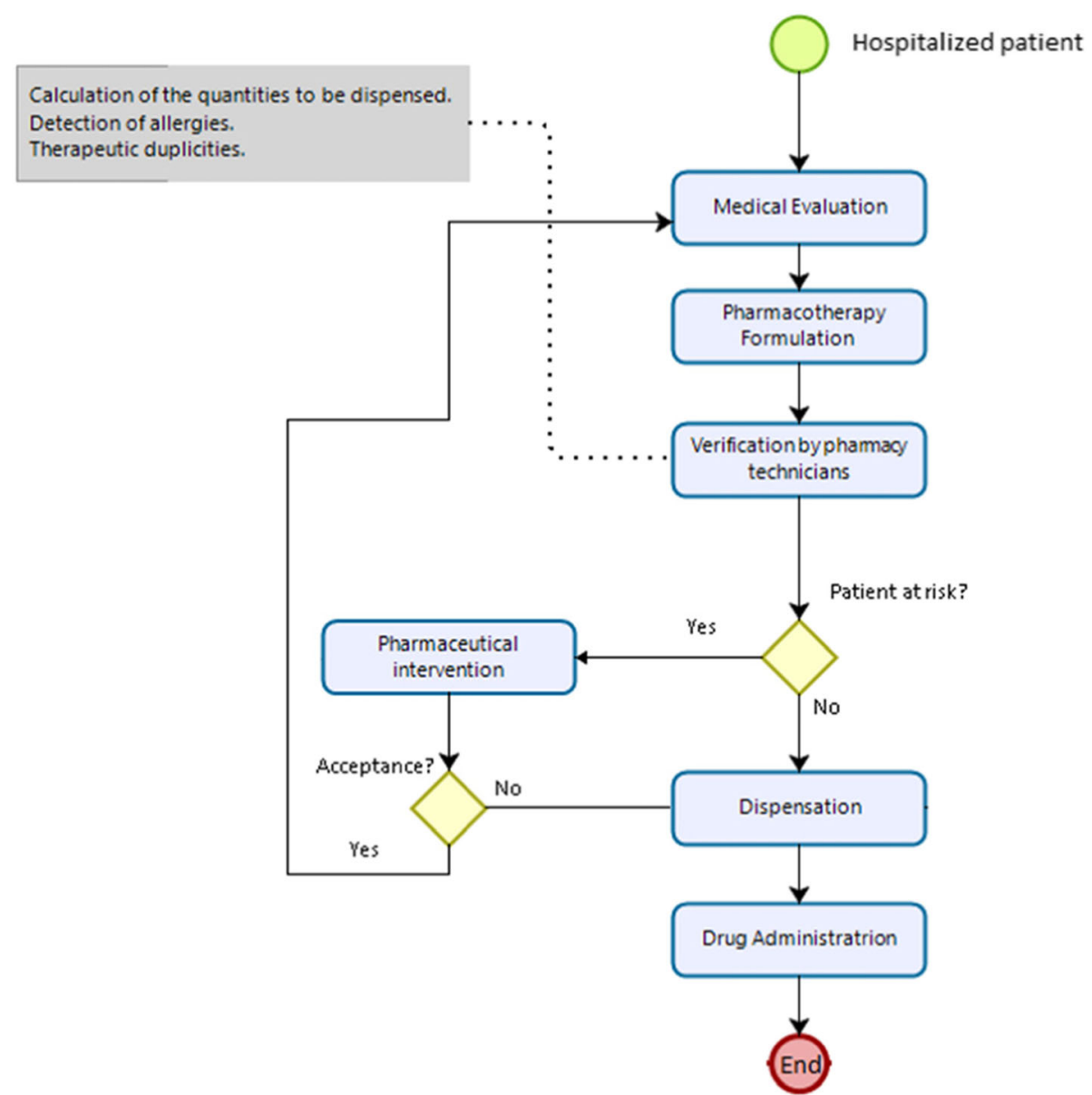

Fig. 3 Usual care process 
Every day, the pharmacist in the morning will provide a list of patients that they must evaluate as specified in activities 2, 3, and 5 or including other patients when necessary or when any patient requires attention. The model is shown in Fig. 3.

\section{Control group}

The usual patient care process includes a medical evaluation and the respective formulation of pharmacotherapy (Fig. 4). Later, the pharmacy technicians will use a spreadsheet to verify the quantities that will be dispensed, allergy detection, therapeutic duplicities, and finally, the medicine will be dispensed.

\section{Limitations and potential bias}

As the collection of the information will be based on the review of medical records, some sub-registries may be present that will affect medication error detection. However, PTUH is an institution accredited by the Joint Commission International, which has made it possible to adequately standardize the process, including the quality of the medical records, which is therefore expected to control this bias.

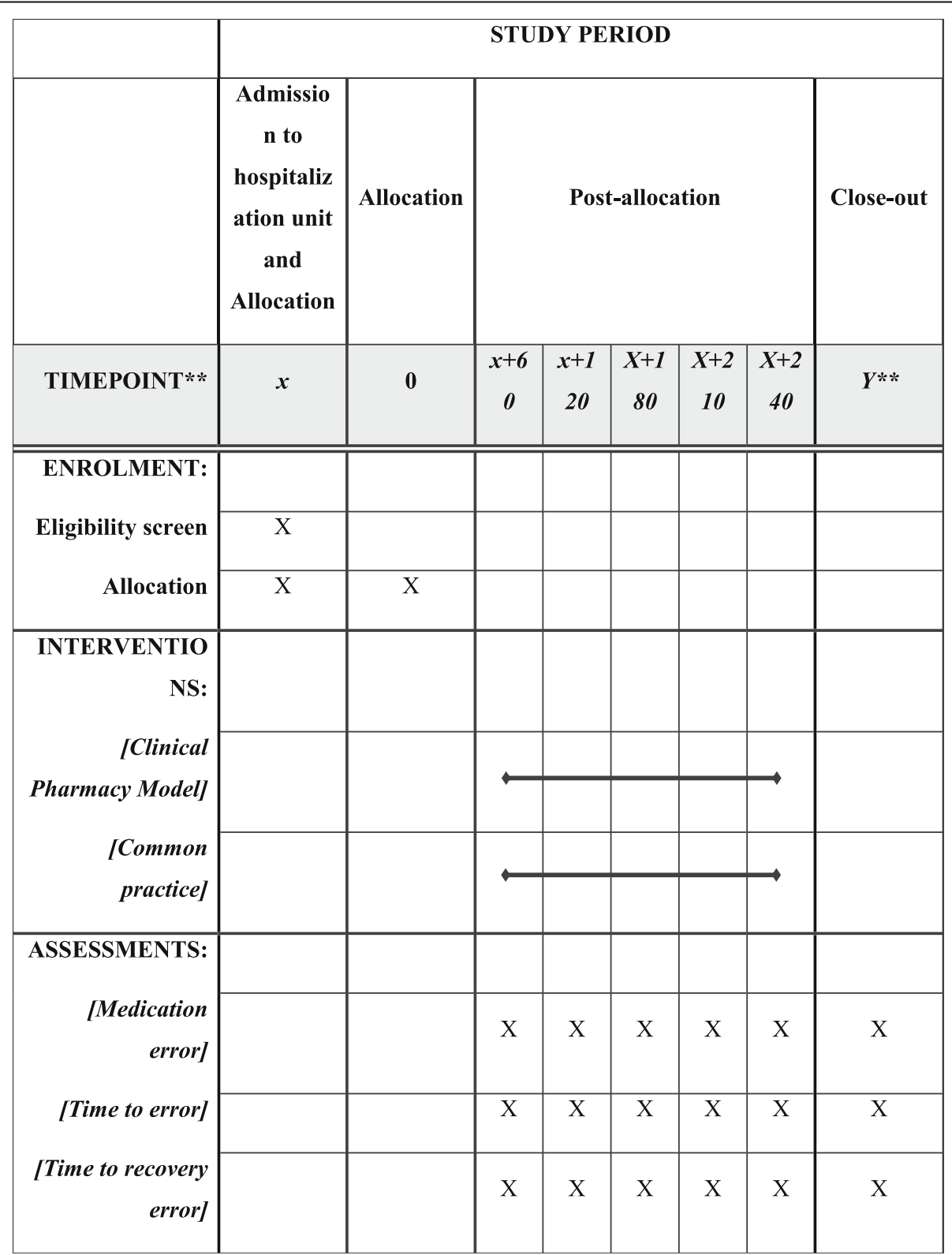

Fig. 4 Standard protocol items: recommendation for interventional trials (SPIRIT) figure. ${ }^{*} \mathrm{X}$ is $1-60$ days (baseline). ${ }^{*} \mathrm{Y}$ is a period after the end of the post-discharge follow-up 


\section{Randomization}

Clusters will be assigned to the intervention group or the control group through a computer-generated randomization sequence, designed by a person external to the study and otherwise unrelated to it, using Micro${\text { soft } \text { Excel }^{\odot} \text { (version 2010, Microsoft }}^{\bullet}$ Corporation, Redmond, Wash.).

\section{Blinding}

An external evaluation group made up of an internist and a pharmacist will be established to evaluate whether a medication error occurred and whether it resolved. This evaluation will be done once the patient's hospitalization has ended and the patient discharged. Additionally, the evaluators will be blinded and will not know if the patients were in the clinical pharmacy model; the notes of the pharmacist in the medical record will not be available.

\section{Sample size calculation}

For the sample size calculation, we use the package SWSamp [20] in R software version 3.2. The overall incidence of medication errors of $15 \%$ was a reference value [21]. The calculation of the sample size was made by accepting an alpha error of 0.05 , a beta error of 0.84 , five clusters, six steps, two months for each step, 24 participants per cluster, and a coefficient of variation $(\mathrm{k})$ of 0.15 . The number of individuals needed to detect a difference equal to or more significant than $10 \%$ was 720 .

\section{Data collection}

Data will be collected from February 2018 to January 2019. The study will extend over 14 months, the recruitment period will be 12 months, and patients will be evaluated for 2 months, starting from the date of their recruitment. Once the enrolment period ends, the final 2 months will be used only to evaluate the latest patients. The data obtained in this study will register in an electronic database. Data regarding the medication history, interviews with the pharmacist, health status, plans of action, as well as the data related to the primary outcome, will be registered.
A specially trained clinical pharmacist and an internist will make up the clinical staff that will accurately measure the medical record of each patient at baseline ( $\mathrm{t} 0), 2$ months post-baseline ( $\mathrm{t} 1$ ), 4 months post-baseline (t2), 6 months post-baseline (t3), 8 months post-baseline (t4), and 10 months post-baseline (t5). The clinical staff will be an external evaluation group that will evaluate if a medication error has occurred and whether it resolves. This evaluation will be done once the patient's hospitalization has ended and the patient discharged.

\section{Data management}

Only the pharmacist and the physician involved in the trial will have access to the data entry software. The data will be controlled and formatted to prevent errors in transcription. Data will be stored in a database PostgreSQL and accessed with software developed in VB.net specifically for the trial. The database includes information about medications and treatments, physical assessment records, laboratory tests, and hospitalizations. The database shows reports of a patient's assessment forms, allows monitoring of data quality, and generates reports according to the user's needs. Researchers involved in this study will be the only ones with access to the information. We will back up the database daily in two different computers to protect the information. Table 2 shows the personnel involved in the study and their function.

\section{Missing data}

We will inspect missing data, and if less than $5 \%$ is missing, we will use imputation by the median values for the continuous variables and mode for the categorical ones.

\section{Statistical analysis}

The statistical analyses of the full-analysis set will follow the intention-to-treat (ITT) principle with $\mathrm{R}$ software version 3.2, using the patient-related observations from the medical records as the unit of analysis, a dataset that includes all subjects in the assigned cluster and meets all inclusion criteria. Baseline and demographic characteristics will be analyzed descriptively (number of valid cases, mean, standard deviation, median, interquartile range,

Table 2 Function of researchers

\begin{tabular}{lll}
\hline Person & Function & Blinding \\
\hline Pharmacist and epidemiology 1 & Database completion & No \\
Pharmacist and epidemiology 2 & Recruitment & No \\
& Database completion & No \\
Pharmacist and statistician & Recruitment & Statistical analysis. \\
& Database completion & Yes \\
Pharmacist & Evaluation of medical records outcome evaluation & Yes \\
Physician & Evaluation of medical records outcome evaluation & \\
\hline
\end{tabular}


and proportions for qualitative variables). A mixed model will evaluate the primary hypothesis with the treatment group and time as the fixed effects and the clustering structure as a random effect. A significance level set to alpha $=5 \%$ (two-sided) will be used to compare proportions. Comparisons for categorical variables will be conducted using the chi-square test (or the Fisher exact test when appropriate) and for continuous variables by using the independent-sample t-test (if the distributions are not typical, as determined by the Kolmogorov-Smirnov test, we will use the MannWhitney U test). Student's t-test (between study groups) will be used to compare means, and the odds ratios (ORs) and 95\% confidence intervals (CIs) will be estimated as well. The mean number and duration of relapse events, normalized to person-time, will be compared between groups using Student's t-test. Multivariate analyses will be performed to explain the association of multiple variables with the factors significantly related to primary outcome. The sociodemographic and clinical variables to be assessed are sex, age, social security system, scholarship, weight, height, allergies, having a caregiver, diagnosis of admission, hospitalization in the previous 6 months, number of services, previous stay in intensive care unit, adverse drug reaction, colonized patient, hospital stay length, and number of medications. Table 3 shows the operationalization of variables, and Table 4 show statistical analysis for outcome.

\section{Discussion}

Medication errors account for approximately $37 \%$ of adverse events that occur during health care [4]. The harm caused by medication errors in poly-medicated patients is frequent, constituting a potential cause of death and increasing the costs associated with health [22]. In the last decade, WHO has focused its efforts on implementing actions aimed at reducing the adverse events related to health care as well as correcting deficiencies that may lead to medication errors and severe damage [23]. Different studies have tried interventions to reduce these errors, which include the development of computerized

Table 3 Operationalization of variables

\begin{tabular}{|c|c|c|c|}
\hline Variable & Operational definition & Nature & $\begin{array}{l}\text { Unit of measurement } \\
\text { (Categorization) }\end{array}$ \\
\hline Sex & Biological condition at birth & $\begin{array}{l}\text { Nominal } \\
\text { qualitative }\end{array}$ & $\begin{array}{l}\text { 1. Man } \\
\text { 2. Woman }\end{array}$ \\
\hline Age & Age in years & Quantitative & Age in years \\
\hline Social security system & Membership social security system & $\begin{array}{l}\text { Nominal } \\
\text { qualitative }\end{array}$ & $\begin{array}{l}\text { 1. Contributory } \\
\text { 2. Subsidized }\end{array}$ \\
\hline Scholarship & Schooling & $\begin{array}{l}\text { Qualitative } \\
\text { ordinal }\end{array}$ & $\begin{array}{l}\text { 1. No studies } \\
\text { 2. Primary } \\
\text { 3. High School } \\
\text { 4. College undergraduate } \\
\text { 5. University postgraduate } \\
\text { degree }\end{array}$ \\
\hline Weight & Patient weight & Quantitative & Weight in Kg \\
\hline Height & Patient height & Quantitative & Height in $\mathrm{cm}$ \\
\hline Allergies & Allergic antecedents & $\begin{array}{l}\text { Nominal } \\
\text { qualitative }\end{array}$ & $\begin{array}{l}\text { 1. Yes } \\
\text { 2. No }\end{array}$ \\
\hline To have caregiver & Family or friend who accompanies during hospitalization & $\begin{array}{l}\text { Nominal } \\
\text { qualitative }\end{array}$ & $\begin{array}{l}\text { 1. Yes } \\
\text { 2. No }\end{array}$ \\
\hline Diagnosis of admission & Admission diagnosis & $\begin{array}{l}\text { Nominal } \\
\text { qualitative }\end{array}$ & - \\
\hline $\begin{array}{l}\text { Hospitalization } 6 \text { months } \\
\text { before }\end{array}$ & Hospitalization 6 months before & $\begin{array}{l}\text { Nominal } \\
\text { qualitative }\end{array}$ & $\begin{array}{l}\text { 1. Yes } \\
\text { 2. No }\end{array}$ \\
\hline Number of services received & Specialties that are treating the patient & Quantitative & Count \\
\hline $\begin{array}{l}\text { Previous stay in intensive care } \\
\text { unit }\end{array}$ & Previous stay in intensive care unit & $\begin{array}{l}\text { Nominal } \\
\text { qualitative }\end{array}$ & $\begin{array}{l}\text { 1. Yes } \\
\text { 2. No }\end{array}$ \\
\hline Adverse drug reaction & Adverse drug reaction & $\begin{array}{l}\text { Nominal } \\
\text { qualitative }\end{array}$ & $\begin{array}{l}\text { 1. Yes } \\
\text { 2. No }\end{array}$ \\
\hline Colonized patient & $\begin{array}{l}\text { Patient isolated unit because a multi-resistant bacterium colo- } \\
\text { nizes him }\end{array}$ & $\begin{array}{l}\text { Nominal } \\
\text { qualitative }\end{array}$ & $\begin{array}{l}\text { 1. Yes } \\
\text { 2. No }\end{array}$ \\
\hline Hospital stay length & Hospitalization days & Quantitative & Count \\
\hline Number of medications & Number of drugs prescribed & Quantitative & Count \\
\hline
\end{tabular}


Table 4 Statistical analysis for outcome

\begin{tabular}{ll}
\hline Type Analysis & Measure \\
\hline Univariate analysis & Population characterization \\
Bi-varied analysis & Estimation of the association (RR) between the clinical pharmacy model and the incidence of medication errors. \\
& The difference of means in the hospital stay length \\
Multivariate analysis & Poisson regression to determine the variables that most influence the MEs. \\
Survival analysis & The difference in time in the presence of a medication error. \\
& The difference in time in the resolution of a medication error.
\end{tabular}

physician order entry (CPOE), use of clinical decision support systems, standardization of protocols for the treatment and management of medication in different health problems, and the implementation of education and training programs for health staff, as well as the incorporation of pharmacists into the patient care team, thereby allowing activities that improve medication safety [24-26]. In another stepped-wedge study, the MEDREV Working Group et al. sought to measure the impact of collaborative pharmaceutical care on preventable medication error rates, but their results are not yet available [27].

Worldwide, different clinical pharmacy models have described multiple strategies from the pharmaceutical view for improving safety inpatient care; however, we did not find results where they evaluated the change in the incidence of medication errors. For that, Pablo Tobón Uribe Hospital, framed under international standards of safety, quality, and care (Joint Commission International), has standardized a clinical pharmacy model contributing to the improvement of the quality of health care, which requires evaluation for determining its effect on the incidence of medication errors.

To our knowledge, no previous randomized controlled trials exist that were designed to evaluate the effect of a clinical pharmacy practice model (CPPM) on the incidence of medication errors (patient safety), and thus, most of these strategies are based on expert recommendations and descriptive studies $[8,28]$. In Colombia, the first and only related RCT, Effectiveness of a Method for Pharmaceutical Care in outpatients with Bipolar disorder, showed the risk of hospitalizations and emergencies was lower for the intervention group [29]. This study is the first stepped-wedge controlled trial designed to assess the effect of the clinical pharmacy practice model on the incidence of medication error in hospitalized patients. Also, this study could generate strong evidence, both theoretical and practical, that the CPPM could contribute to reducing medication errors in hospitalized patients. The stepped-wedge design was selected for this trial due to the variability of the hospitalization wards (clusters) and their complexity in the clinical and pharmacological management of the patients. In this methodology, all clusters are first placed in the control group and then move to an intervention group, conserving power, unlike parallel studies in which power changed by the increased variability in the groups [30,31].

\section{Abbreviations}

ADR: adverse drug reactions; CPPM: clinical pharmacy practice model; IRB: institutional review board; ITT: intention to treat; ME: medication errors; NCC MERP: National Coordinating Council of Medication Error Reporting and Prevention; PTUH: Pablo Tobón Uribe Hospital; WHO: World Health Organization

\section{Acknowledgements}

We want to thank the Clinical Pharmacy Section, Pharmacy Department, Pablo Tobón Uribe Hospital, Medellín, Colombia. The authors express their gratitude to the Department of Pharmacy, the Faculty of Pharmaceutical and Food Sciences, and the University of Antioquia for supporting the project, as well as to the pharmacist Yasmith Manosalva and the physician Natalia Zapata for their contributions to the patient evaluations.

\section{Trial status}

This study is currently recruiting patients

Protocol version 0016052017JG (9 February 2018).

The first patient recruitment occurred on 2 February 2018.

Recruitment will be completed in March or April 2019.

\section{Authors' contributions}

$J \mathrm{G}$ is the principal investigator, and he developed the original idea for this research. JG, JPB-A, NO, and PA designed the study. JG and AV contributed to the creation of the protocol. AS-O and PA also contributed to the creation of the protocol and are members of the tutorial committee of the Ph.D. student. JPB contributed to the implementation of the project's administrative activities, which were performed at the clinic. All authors read and approved the final manuscript

\section{Authors' information}

JG is a Pharmacist, MSc, and Ph.D. student in Food and Pharmaceutical Sciences, at the University of Antioquia.

PA is a Ph.D., Pharmacist, and Professor at the University of Antioquia, Medellin, Antioquia, Colombia.

ASO is a Ph.D., Pharmacist, and Professor at the University of Antioquia, Medellin, Antioquia, Colombia.

JPB is a Pharmacist, MSc, and Head of the Clinical Pharmacy Section, Pharmacy Department in the Pablo Tobón Uribe Hospital, Medellín, Colombia.

AFV is a Pharmacist in the Clinical Pharmacy Section, Pharmacy Department in the Pablo Tobón Uribe Hospital, Medellín, Colombia.

NO is a Pharmacist in the Clinical Pharmacy Section, Pharmacy Department in the Pablo Tobón Uribe Hospital, Medellín, Colombia.

\section{Funding}

The Pharmaceutical Promotion and Prevention Group received financial support from the Committee for Development Research (CODI) and the sustainability program (2018-2019), Universidad de Antioquia.

Ethics approval and consent to participate

The trial will be carried out in compliance with the protocol and the declaration of Helsinki, in accordance with the International Conference on 
Harmonization. The Institutional Review Board (IRB) of the Pablo Tobón Uribe Hospital approved the protocol (cod 2017.050/2017). Data will be collected from clinical records, and the proposed intervention does not entail the risk of causing biological, psychological, or social damage, with all the clusters, in the end, having this intervention. Due to the nature of the study and according to the Colombian laws (resolution number 8430 of 1993), this study has been considered without risk for participants, and informed consent formulary was waived.

\section{Competing interests}

The authors declare they do not have any potential conflicts of interest concerning the authorship or publication of this article. Data are being collected by JGV and will be interpreted by JGV, PA, JPD, NO, and ASO. JGV, $\mathrm{PA}, J \mathrm{BD}$, and ASO will write the paper.

\section{Author details}

'Grupo Promoción y Prevención Farmacéutica, Facultad de Ciencias Farmacéuticas y Alimentarias, Universidad de Antioquia, Calle 70 No 52-21, Medellín, Colombia. ${ }^{2}$ Grupo de investigación en Tecnología en Regencia de Farmacia, Universidad de Antioquia U de A, Calle 70 No 52-21, Medellín, Colombia. ${ }^{3}$ Grupo Investigación clínica HPTU., Hospital Pablo Tobón Uribe, Calle 78B \#69-240, Medellín, Antioquia 05001000, Colombia.

Received: 23 December 2018 Accepted: 2 December 2019

Published online: 06 January 2020

\section{References}

1. Kohn LT, Corrigan J, Donaldson MS, editors. To err is human: building a safer health system. Washington, D.C.: National Academy Press; 2000.

2. Johnson JA, Bootman JL. Drug-related morbidity and mortality. A cost-ofillness model. Arch Intern Med. 1995;155(18):1949-56.

3. Makary MA, Daniel M. Medical error-the third leading cause of death in the US. BMJ. 353:i2139. https://doi.org/10.1136/bmj.i2139.

4. McLeod M, Barber N, Franklin BD. Facilitators and barriers to safe medication administration to hospital inpatients: a mixed methods study of nurses' Medication Administration Processes and Systems (the MAPS Study). PLoS. One. 2015;10(6):e0128958

5. Elden NMK, Ismail A. The importance of medication errors reporting in improving the quality of clinical care services. Glob J Health Sci. 2016;8(8): 243-51

6. World Health Organization. World Alliance for Patient Safety: forward programme 2008-2009. Geneva: World Health Organization; 2008. Report No.: WHO/IER/PSP/2008.04. http://apps.who.int/iris/handle/10665/70460. Accessed 29 Oct 2018

7. World Health Organization. World alliance for patient safety: forward programme. Geneva: World Health Organization; 2005.

8. Pickette SG, Muncey L, Wham D. Implementation of a standard pharmacy clinical practice model in a multihospital system. Am J Health Syst Pharm. 2010;67(9):751-6.

9. Zellmer WA, Cobaugh DJ, Chen D. Three signals from the Pharmacy Practice Model Summit. Am J Health Syst Pharm. 2011;68(12):1077.

10. SHPA Committee of Specialty Practice in Critical Care. SHPA standards of practice for critical care pharmacy practice. J Pharm Pract Res. 2008;38(1): 58-60.

11. The Society of Hospital Pharmacists of Australia (SHPA). Standards of practice for clinical pharmacy services. Soc Hosp Pharm Aust SHPA. J Pharm Pract Res. 2005:35(2):122-46.

12. Canadian Pharmacists Association. Blueprint for pharmacy: the vision for pharmacy. 2008; https://www.pharmacists.ca/cpha-ca/assets/File/pharmacyin-canada/blueprint/The\%20Vision\%20for\%20\%20Pharmacy_Apr\%201\%2009. pdf. Accessed 1 June 2018

13. Chamoun NR, Zeenny R, Mansour H. Impact of clinical pharmacy interventions on medication error nodes. Int J Clin Pharm. 2016;38(6):1436-44.

14. Bond CA, Raehl CL, Franke T. Clinical pharmacy services, hospital pharmacy staffing, and medication errors in United States hospitals. Pharmacotherapy. 2002:22(2):134-47.

15. Leape LL, Cullen DJ, Clapp MD, Burdick E, Demonaco HJ, Erickson Jl, et al. Pharmacist participation on physician rounds and adverse drug events in the intensive care unit. JAMA. 1999;282(3):267-70.
16. Aguirre JPB, Quintero AFV, Vega EJG. Redesign of the clinical pharmacy practice model in a tertiary academic hospital in Medellín, Colombia. Can J Hosp Pharm. 2017;70(3):225-31.

17. OMS | La OMS lanza una iniciativa mundial para reducir a la mitad los errores relacionados con la medicación en cinco años. WHO. http://www. who.int/mediacentre/news/releases/2017/medication-related-errors/es/. Accessed 7 May 2017

18. Hemming $\mathrm{K}$, Taljaard M, Forbes G, Eldridge SM, Weijer C. Ethical implications of excessive cluster sizes in cluster randomised trials. BMJ Qual Saf. 2018; 27(8):664-70.

19. Lorenz E, Köpke S, Pfaff H, Blettner M. Cluster-randomized studies. Dtsch Arzteblatt Int. 2018;115(10):163-8.

20. giabaio/SWSamp. GitHub. https://github.com/giabaio/SWSamp. Accessed 30 Oct 2019.

21. Pastó-Cardona L, Masuet-Aumatell C, Bara-Oliván B, Castro-Cels I, ClopésEstela A, Pàez-Vives F, et al. Estudio de incidencia de los errores de medicación en los procesos de utilización del medicamento: prescripción, transcripción, validación, preparación, dispensación y administración en el ámbito hospitalario. Farm Hosp. 2009;33(5):257-68.

22. National Coordinating Council for Medication Error Reporting and, Prevention. NCC MERP Taxonomy of medication errors. Available from: http://www.nccmerp.org/sites/default/files/taxonomy2001-07-31.pdf. Accessed 1 June 2018

23. OMS | La OMS lanza 'Nueve soluciones para la seguridad del paciente' a fin de salvar vidas y evitar daños. WHO. http://www.who.int/mediacentre/ news/releases/2007/pr22/es/. Accessed 15 Apr 2016.

24. Perez A, Doloresco F, Hoffman JM, Meek PD, Touchette DR, Vermeulen LC, et al. ACCP: economic evaluations of clinical pharmacy services: 2001-2005. Pharmacotherapy. 2009;29(1):128.

25. Salazar L. N, Rojas A L, Jirón Aliste MC, Romero P. C. Errores de medicación en la Unidad de Cuidados Intensivos. 2012. http://repositorio.uchile.cl/ handle/2250/124258. Accessed 29 Oct 2018.

26. Boostani K, Noshad H, Farnood F, Rezaee H, Teimouri S, Entezari-Maleki T, et al. Detection and management of common medication errors in internal medicine wards: impact on medication costs and patient care. Adv Pharm Bull. 2019;9(1):174-9.

27. MEDREV Working Group, Leguelinel-Blache G, Castelli C, Roux-Marson C, Bouvet $\mathrm{S}$, Andrieu $\mathrm{S}$, et al. Impact of collaborative pharmaceutical care on in-patients' medication safety: study protocol for a stepped wedge cluster randomized trial (MEDREV study). Trials. 2018;19(1):19.

28. Lorimer HJ, Lalli SL, Spina SP. Redesign of the pharmacy practice model at a tertiary care teaching hospital. Can J Hosp Pharm. 2013;66(1):28-34.

29. Salazar-Ospina A, Amariles P, Hincapié-García JA, González-Avendaño S, Benjumea DM, Faus MJ, et al. Effectiveness of the Dader method for pharmaceutical care on patients with bipolar i disorder: results from the EMDADER-TAB Study. J Manag Care Spec Pharm. 2017;23(1):74-84.

30. Campbell MK, Thomson S, Ramsay CR, MacLennan GS, Grimshaw JM. Sample size calculator for cluster randomized trials. Comput Biol Med. 2004; 34(2):113-25.

31. Hemming K, Haines TP, Chilton PJ, Girling AJ, Lilford RJ. The stepped wedge cluster randomised trial: rationale, design, analysis, and reporting. BMJ. 2015; 350(1):h391

\section{Publisher's Note}

Springer Nature remains neutral with regard to jurisdictional claims in published maps and institutional affiliations.

Ready to submit your research? Choose BMC and benefit from:

- fast, convenient online submission

- thorough peer review by experienced researchers in your field

- rapid publication on acceptance

- support for research data, including large and complex data types

- gold Open Access which fosters wider collaboration and increased citations

- maximum visibility for your research: over $100 \mathrm{M}$ website views per year

At $\mathrm{BMC}$, research is always in progress.

Learn more biomedcentral.com/submission 